\title{
ÉTICA NO FAZER PROFISSIONAL DA ENFERMAGEM: REFLEXÕES À LUZ DO PENSAMENTO DE HANNAH ARENDT
}

\author{
ETHICS IN THE NURSING PROFESSIONAL ACTVITY: \\ REFLECTIONS IN THE LIGHT OF HANNAH ARENDT \\ THOUGHT
}

\section{ÉTICA EN LA LABOR DEL PROFESIONAL DE LA ENFERMERÍA: REFLEXIONES A LA LUZ DEL PENSAMIENTO DE HANNAH ARENDT}

\author{
Camila Biazus Dalcin ${ }^{1}$ \\ Rafaela Serpa ${ }^{2}$ \\ Evangelia Kotzias Atherino dos Santos ${ }^{3}$ \\ Francis Solange Vieira Tourinho ${ }^{4}$ \\ Patrícia Kuerten Rocha ${ }^{3}$
}

Como citar este artigo: Dalcin CB, Serpa R, Santos EKA, Tourinho FSV, Rocha PK. Ética no fazer profissional da enfermagem: reflexões à luz do pensamento de Hannah Arendt. Rev baiana enf. 2019:33:e29654.

\begin{abstract}
Objetivo: refletir sobre a ética no fazer profissional da enfermagem, levando em consideração os conceitos de condição humana e a banalidade do mal de Hannah Arendt. Método: reflexão teórico-filosófica. Resultados: o pensamento crítico reflexivo deve ser parte do fazer profissional da enfermagem, para que seja aceita a condição humana - o labor, o trabalho e a ação - da ética no cuidado, evitando, assim, fragmentações, erros e mecanização do cuidado de enfermagem. A banalidade do mal pode ser transposta por meio da educação permanente e continuada do profissional de enfermagem. Conclusão: ao utilizar conceitos do pensamento de Hannah Arendt, percebe-se a importância de que o profissional da enfermagem assuma uma postura crítico-reflexiva e ética de não julgamento, destacando-se que a educação em saúde, trabalho em equipe e sentimento de pertencimento à profissão de enfermagem, são elementos importantes para o fortalecimento profissional.
\end{abstract}

Descritores: Ética. Ética em Enfermagem. Prática Profissional. Filosofia em Enfermagem. Ética Profissional. Cuidados de Enfermagem.

Objective: to reflect on the ethics of the professional nursing practice, taking into account the concepts of the buman condition and the banality of Hannah Arendt's evil. Method: A theoretical and philosophical reflection. Results: reflective critical thinking must be part of the professional nursing practice, in order to accept the buman condition - labor, work and action - of ethics in care, thus avoiding fragmentation, errors and mechanization in nursing care. The banality of the evil can be overcome through the continuing and continuing education of the nursing professional. Conclusion: using concepts from Hannah Arendt's thinking, the importance of nursing professionals

Enfermeira. Mestre em Enfermagem. Universidade Federal de Santa Catarina. Florianópolis, Santa Catarina, Brasil. camilabiazus@hotmail.com

Enfermeira. Especialista em Urgência, Emergência e APH. Técnica de enfermagem no Hospital Universitário Polydoro Ernani de São Thiago. Florianópolis, Santa Catarina, Brasil.

Enfermeira. Doutora em Enfermagem. Professora da Universidade Federal de Santa Catarina. Florianópolis, Santa Catarina, Brasil.

${ }^{4}$ Enfermeira. Doutora em Saúde da Criança e do Adolescente. Professora da Universidade Federal de Santa Catarina. Florianópolis, Santa Catarina, Brasil. 
assuming a critical-reflexive posture and non-judgmental ethics is highlighted, highlighting that health education, teamwork and a sense of belonging to the profession nursing, are important elements for professional strengthening.

Descriptors: Ethics. Ethics in Nursing. Professional Practice. Philosophy in Nursing. Professional Ethics. Nursing Care.

Objetivo: reflexionar sobre la ética en la labor de los profesionales de la enfermería, considerando los conceptos de la condición bumana y la banalidad del mal de Hannah Arendt. Método: reflexión teórico-filosófica. Resultados: el pensamiento crítico reflexivo debe ser parte de la labor de los profesionales de la enfermería, para que se acepte la condición humana (la labor, el trabajo y la acción) de la ética del cuidado; para así evitar fragmentaciones, errores y la mecanización del cuidado de enfermería. La banalidad del mal puede trasponerse por medio de la educación permanente y continuada del profesional de la enferme. Conclusión: al emplear conceptos del pensamiento de Hannah Arendt, se percibe la importancia de que el profesional de enfermería asuma una postura crítico-reflexiva y ética de no emitir juicios, destacándose que la educación en salud, el trabajo en equipo y el sentimiento de pertenencia a la profesión de enfermería son elementos importantes de fortalecimiento profesional.

Descriptores: Ética. Ética en Enfermería. Práctica Profesional. Filosofía en Enfermería. Ética Profesional. Cuidados de Enfermería.

\section{Introdução}

A enfermagem compreende um componente próprio de conhecimento científico e técnico, construído e reproduzido por um conjunto de práticas sociais, éticas e políticas, que se processa pela assistência, ensino, pesquisa e gestão. Os profissionais que atuam nessa área da saúde prestam serviços às pessoas, famílias e coletividade, em seus diferentes contextos e circunstâncias de vida ${ }^{(1)}$. Por meio de uma assistência integral e efetiva, a enfermagem, em sua essência, cuida do ser humano de modo multidimensional ${ }^{(2)}$.

No Brasil, a Enfermagem é uma profissão constituída majoritariamente por mulheres, que representam a maior força de trabalho na área saúde. Está presente ao lado do paciente, seja em serviço público ou privado, 24 horas por dia, nos 365 dias do ano ${ }^{(3)}$. Com essa compreensão, pode-se afirmar que a enfermagem é uma profissão com ampla abordagem e atuação, não podendo ser entendida apenas pela virtude da técnica, mas também da prática, da cientificidade, de sua posição política e social, como também econômica, ética e estética de cuidar do outro, como produto do fazer profissional. A enfermagem visa a melhora do outro como seu fazer profissional $^{(1,4)}$.

Sendo esta uma profissão comprometida com o conceito ampliado de saúde e a qualidade de vida das pessoas, atua na promoção, prevenção, recuperação e reabilitação da saúde no contexto do Sistema Único de Saúde (SUS) ${ }^{(5)}$. A equipe de enfermagem, constituída pelo enfermeiro, técnico de enfermagem, auxiliar de enfermagem e parteira, participa em diversos níveis de atenção. No exercício de suas funções, o faz com autonomia e em consonância com os preceitos éticos e legais da profissão ${ }^{(1)}$.

Com relação às questões éticas e legais da profissão de enfermagem, percebe-se a importância da temática no fazer diário profissional. Essas questões associam-se com situações organizacionais, situações clínicas complexas e situações interpessoais, causando sofrimento moral no profissional que atua na área ${ }^{(6-8)}$. É importante ressaltar a complexidade da ética no fazer profissional e a necessidade de buscar reflexões ampliadas, pois a ética é uma inteligência coletiva que estabelece os princípios para a boa convivência de uma sociedade, que existe porque há liberdade. Não é um conjunto determinado de leis; é uma reflexão sobre aquilo que um grupo social escolhe, durante um período de tempo, como referência de comportamento. Devido à constante transformação da sociedade, com valores nem sempre absolutos, o pensamento ético deve ser refletido no cotidiano dos grupos sociais, entre eles o da enfermagem ${ }^{(9)}$. 
O aprimoramento do comportamento ético dessa complexa profissão é essencial e passa pelo processo de construção de uma consciência individual e coletiva, pelo compromisso social e profissional que se expressa na responsabilidade no plano das relações de trabalho com reflexos no campo científico e político ${ }^{(1)}$. Nesse sentido, as ações dos profissionais da enfermagem devem estar fundamentadas na ética, levando em consideração o compromisso com a pessoa que busca os serviços de saúde e seus direitos, os valores da profissão e o código de ética, integrando cuidado qualificado e o respeito pelo livre consentimento e pela promoção do paciente como um protagonista e sujeito do cuidado $^{(10)}$.

A preocupação da enfermagem brasileira com uma nova ética, isto é, uma forma de pensar que preserve os princípios básicos da enfermagem e se adapte ao mundo moderno, por exemplo, por meio da inclusão das mídias sociais, para pautar a conduta do profissional da enfermagem, nesse contexto, precisa ser ampliada. Uma abordagem moderna para a ética na enfermagem necessita de um fazer profissional fundamentado nos valores profissionais e nas prioridades da pessoa assistida. Estudos quantitativos e qualitativos corroboram a necessidade de discussão acerca das questões éticas no fazer profissional da enfermagem, por meio de reflexões ampliadas em conceitos e princípios teóricos ${ }^{(11-13)}$. Questões cotidianas, como educação, relações interpessoais e no trabalho, permeiam o questionamento a respeito da enfermagem, se realmente tem um domínio teórico da ética e quais as suas especificidades.

Assim, a fim de modificar os paradigmas existentes acerca do fazer profissional, a busca por referenciais inovadores e ampliados é necessária para abordar questões complexas e emergentes da contemporaneidade, como a ética no fazer da Enfermagem. Para tanto, pode-se buscar auxílio em outras disciplinas, como as ciências políticas e a filosofia, com o intuito de ampliar conhecimentos na ciência da enfermagem e da saúde. Acredita-se que alguns dos princípios filosóficos e políticos de Hannah Arendt podem contribuir para olhar os problemas éticos da enfermagem com o auxílio de um referencial teórico-filosófico contemporâneo e inovador, a fim de possibilitar novas resoluções para antigas problemáticas do fazer profissional. Revela-se um essencial desafio repensar esse fazer à luz do pensamento de Hannah Arendt, especialmente no que se refere aos conceitos de condição humana e banalidade do mal, para que se possa buscar novas estratégias para desafios éticos profissionais.

Este estudo tem como objetivo refletir sobre a ética no fazer profissional da enfermagem, levando em consideração os conceitos de condição humana e banalidade do mal de Hannah Arendt.

\section{Método}

Reflexão teórico-filosófica fundamentada nos conceitos de banalidade do mal e condição humana de Hannah Arendt. Este estudo de reflexão emergiu das discussões realizadas na disciplina optativa dos Cursos de Doutorado e Mestrado em Enfermagem intitulada "Filosofia da Ciência da Enfermagem e Saúde" do Programa de Pós-Graduação em Enfermagem da Universidade Federal de Santa Catarina (UFSC). Para conclusão da disciplina, foi proposta a realização de uma reflexão teórico-filosófica, sob a forma de um manuscrito, acerca de um dos temas abordados na disciplina, aproximando-a da enfermagem. As reflexões de Hannah Arendt emergiram como essenciais para a condição humana e as questões éticas emergentes no fazer profissional da enfermagem e foi uma escolha teórica. Leituras aprofundadas do referencial teórico foram realizadas e o acesso aos materiais ocorreu por indicação de expertises na área e pela busca em bases de dados on-line. Logo, emergiu a importância de refletir sobre os conceitos de condição humana e de banalidade do mal de Hannah Arendt, a fim de ampliar e aprofundar as discussões acerca da prática da enfermagem. A condição humana traz como propósito a reflexão sobre o que estamos fazendo e nos chama a re-considerar a condição humana baseada em nossas experiências e nossos temores mais recentes. 


\section{Resultados e discussão}

Neste estudo, emergiram duas categorias: Hannah Arendt, a condição humana e a banalidade do mal; e Reflexões acerca da ética no fazer profissional da enfermagem por meio de conceitos da pensadora Hannah Arendt. Na primeira categoria, foram apresentados e discutidos os conceitos de condição humana e banalidade do mal, os quais embasaram este estudo. Na segunda categoria, foi discutida a aplicação desses dois conceitos na prática profissional.

\section{Hannab Arendt, a condição humana e a banalidade do mal}

A alemã Hannah Arendt, filósofa e pensadora política contemporânea, nascida em 1906, era de descendência judia. Durante a Segunda Guerra Mundial, foi para os Estados Unidos da América, onde atuou como professora Universitária e autora de diversos livros ${ }^{(11-13)}$. Para as discussões teórico-filosóficas acerca da ética no fazer da enfermagem, as reflexões serão baseadas nos conceitos de condição humana e banalidade do mal.

Hannah Arendt faz reflexões profundas acerca da condição humana associada à sociedade operária, na qual os seres humanos encontram-se inseridos. Para a autora, a condição humana são as formas de vida que o ser humano impõe a si mesmo para viver e sobreviver, sendo diferente de natureza humana. A expressão da pensadora vita activa, inclui três atividades humanas essenciais: o labor (processo biológico do corpo humano); o trabalho (atividade que corresponde ao artificialismo da existência humana, expressa pela produção de um mundo artificial de coisas diferentes do que é dado pelo ambiente natural); e a ação (única atividade entre os seres humanos sem mediação de coisas ou matérias, sendo todos humanos e diferentes - o social, que é a condição de toda a vida política) ${ }^{(11)}$. Tais atividades são essenciais, pois a cada uma delas corresponde uma das condições básicas mediante as quais a vida foi dada ao ser humano na Terra.

A centralidade da vida no trabalho faz com que os elementos que o constituem sejam construídos, desconstruídos e repensados com base nele. Com relação à revelação do agente no discurso e na ação, percebe-se que a pluralidade humana é necessária para a composição da ação e do discurso, com duplo sentido no aspecto da igualdade e da diferença. Nesse contexto, os seres humanos precisam do discurso e da ação para se fazerem entender ${ }^{(13)}$.

A ação humana é um processo que está intimamente ligado ao fato de as pessoas viverem juntas. Para se ter uma ação, Hannah defende a necessidade intrínseca de uma sociedade, isto é, da relação de um ser humano com outro ser humano. Dessa forma, o homem é um animal social e político. Essa maneira de pensar vem associada a questões já discutidas desde Aristóteles na Grécia antiga, quando ele descreveu o homem como um animal socialis ${ }^{(11)}$.

Essa pensadora discute ainda questões importantes para a ética, amplamente utilizadas nas disciplinas do direito e da educação, como a necessidades de manter uma sociedade coesa, por meio do sentimento de pertencimento. Pelo uso da palavra, da ação e da liberdade, Arendt retrata ser possível uma esperança de democracia ${ }^{(12)}$.

Outra correlação com as questões éticas e morais está associada às reflexões realizadas pela pensadora alemã acerca da banalidade do mal, que surgem durante a cobertura do julgamento do judeu Adolf Eichmann, em Jerusalém, que estava sendo julgado por gerir a logística de deportações em massa dos judeus durante o holocausto. No livro "Einchmann em Jerusalém"(13), Hannah observa a não reflexão do homem que estava sendo julgado, que seguia ordens e não raciocinava sobre suas atitudes/ações. Dessa observação, identifica as implicações da relação entre a falta do pensamento e a banalidade do mal, isto é, na ausência do pensamento nas ações, o mal torna-se banal. Quando um ser humano recusa-se a pensar sobre as atitudes/ ações que está realizando - assume-se como um medíocre -, está recusando a sua essência de ser pessoa, levando à massificação da sociedade. Com relação ao fenômeno da banalidade do mal, argumenta a autora que as pessoas consideradas com comportamentos normais - como Eichmann - podem tomar atitudes monstruosas 
em contextos específicos, pela ausência da reflexão ${ }^{(13)}$. A preocupação de Hannah Arendt é demonstrar como a incapacidade de pensar está relacionada com o ambiente privilegiado para o fracasso moral. Como a enfermagem é uma profissão dedicada ao cuidado integral ao ser humano, no qual o seu fazer é um fenômeno abrangente, interativo e associativo, as dimensões do cuidado revelam a complexidade das questões profissionais ${ }^{(14-15)}$. Na realidade diária enfrentada pelos profissionais de enfermagem, em seus diversos dilemas éticos, quando sob condições de trabalho desfavoráveis, como falta de materiais, número de leitos abaixo da demanda, dimensionamento de pessoal inadequado, a preocupação ética deveria ser gerada nesse fazer. Logo, os profissionais tendem a tornar-se máquinas reprodutivas que desempenham atividades, sem refletir sobre as atitudes e condições impostas ${ }^{(16-17)}$.

Nesse caso, o mal pode ser visto numa perspectiva ética e política. O fenômeno da banalidade do mal está associado a uma dissociação entre o conhecimento e o pensamento, no qual o ser humano transforma-se numa máquina reprodutora de atividades e desprovida de raciocínio, em que a superficialidade e o mecanicismo são imperativos. No discurso que faz do homem um ser político, seguir regras sem a reflexão crítica, faria o discurso não importante ${ }^{(16)}$.

\section{Reflexões acerca da ética no fazer profissional da enfermagem por meio de conceitos da pensadora Hannab Arendt}

A profundidade das questões éticas presentes no fazer profissional da Enfermagem transcende a assistência em si. Tem relação também com as atividades desenvolvidas pela equipe profissional e a forma como o líder, neste caso, o enfermeiro, vai organizar as relações de poder entre seus membros ${ }^{(13-17)}$. Por exemplo, em questões associadas à segurança do paciente, os erros ou eventos adversos não são registrados ou informados, por medo de represálias. Entretanto, revela-se necessária a seguinte reflexão: Quem nunca cometeu um erro ou sentiu-se inseguro na realização de um procedimento? Será que devo julgar e não tentar compreender o outro? Isso pode gerar um sentimento de "tempos sombrios" dentro das instituições de saúde, pois as pessoas não têm confiança nem o hábito de discutir, conversar e refletir sobre suas ações.

Nesse processo, Hannah Arendt revela a importância do compreender as situações, levando em conta o seu contexto multidimensional, para tentar evitar problemas futuros. Como no caso de Eichmann, no qual ela destaca que o entender é necessário, mesmo que não seja uma aceitação da atitude, para tentar evitar que situações iguais aconteçam no futuro. Considerando que a profissão de Enfermagem lida com seres humanos e que erros profissionais podem trazer danos permanentes e custar uma vida, é preciso refletir sobre os múltiplos fatores envolvidos no processo do errar. Entre eles, as condições precárias de trabalho, a falta de materiais, a falta de profissionais, o não apoio institucional, o não apoio do gestor, a falta de protocolos, entre outros ${ }^{(18)}$. Esses fatores mostram que, muitas vezes, a culpabilidade interpretada como negligência, imperícia ou imprudência, não pode ser atribuída a apenas um indivíduo, no caso, o profissional de enfermagem, mas considerar todos os fatos que envolvem o processo de cuidar. Cabe ressaltar que não estamos isentando o profissional de responsabilidade individual, mas tentando compreender a complexidade da dinâmica do fazer profissional que pode levar a uma situação de agravo ${ }^{(16,19)}$.

No trabalho em saúde, considera-se que as decisões profissionais sempre implicam em intervenções sobre outros seres humanos e na qualidade de vida desses, os quais, muitas vezes, encontram-se em situação de fragilidade/vulnerabilidade $^{(7-8)}$. Nesse sentido, o cuidado é também problematizado em seu conteúdo ético, sendo essencial uma reflexão frequente sobre a responsabilidade profissional e social, uma vez que a Enfermagem é uma atividade correlacionada com a essência de sobrevivência do ser humano.

Contudo, o fazer cotidiano está interligado à ética profissional, quando, na assistência, o profissional de enfermagem depara-se com 
situações em que necessita estabelecer prioridades de atendimento. Os dilemas éticos diários, as condições precárias a que estão expostos, levam a pensar e refletir sobre as ações profissionais, que devem estar pautadas no código de ética profissional ${ }^{(20-22)}$, o qual, por nortear e direcionar as ações dos profissionais de enfermagem, deveria perpassar todo o período da formação ${ }^{(14)}$.

Atualmente, questões associadas à ética profissional nas redes sociais revelam-se importantes e necessitam de maior aprofundamento sobre a responsabilidade ética e coletiva em mídias sociais, como Facebook, Twitter e WhatsApp ${ }^{(23-24)}$. Uma revisão integrativa ${ }^{(23)}$ revelou que os profissionais da enfermagem usam essas ferramentas para pesquisar, ensinar e assistir. Entretanto, os profissionais precisam refletir sobre o impacto das mídias sociais no contexto profissional. Para tanto, necessita-se de maiores estudos sobre a temática, a fim de evitar que a internet torne-se outro contexto de esquecimento da condição humana do profissional da saúde e da condição humana dos pacientes nesses cenários. Acredita-se serem importantes reflexões ampliadas sobre a temática, para permitir o pensamento ampliado da atuação pessoa/profissional nas redes sociais.

Diante disso, é importante reconhecer que é complexa a sociedade operária dentro da condição humana do fazer profissional da enfermagem. É preciso entender que o trabalho é uma essência do ser humano, no qual a sua exaustão e o sentimento de não pertencimento à profissão podem levar a uma redução do seu processo de pensar. Percebe-se que, na enfermagem, o profissional não pode renunciar a ser uma pessoa, com seus sentimentos e seu senso crítico. Isso revela-se importante para evitar que o profissional da enfermagem permaneça nas repetições, para encaixar-se no sistema. Com a valorização do processo de pensar individual, será possível um profissional com pensamento crítico-reflexivo nos diferentes contextos em que estão inseridos. Assumir uma postura crítico-reflexiva e ética de não julgamento revela-se relevante para alterar o comportamento de culpabilização profissional. Logo, poderão ser encontradas estratégias para compreender o outro, pensar de forma diferente, e, assim, evitar erros e antecipar dilemas futuros.

Esse processo de pensar pode evitar que ocorra a mecanização e fragmentação do cuidado, o que pode gerar a falta de humanização, o aumento do risco de erros e a diminuição da qualidade da assistência em saúde de forma geral. A banalidade do mal, na enfermagem, está ligada ao processo de mecanização do trabalho, no qual se revela necessário o pensamento crítico, em especial nas situações de erro, pois estes podem ocorrer no fazer de todos os seres humanos. Estes, por alguma falha no processo de reflexão crítica, por diversos motivos, inclusive a renúncia do pensar, podem ser incapazes de dar significado aos acontecimentos e aos seus atos $^{(16-18)}$. Hannah Arendt ${ }^{(11)}$ argumenta que a ausência do pensamento - though-tlessness - é uma despreocupação negligente, que torna o pensar e o fazer vazios. Para sair dessa condição, ela propõe pensar sobre a prática, pensar sobre o que se faz.

Uma das estratégias que se propõe para trabalhar a banalidade do mal na Enfermagem é a educação permanente e continuada em saúde, utilizando metodologias ativas e inovadoras, nas quais o profissional, por meio do pensar crítico, coloca-se na situação de querer aprender, e as instituições de saúde, na situação de querer ensinar. Esse processo deve ser circular e interativo, para que ocorra a troca de conhecimentos e opiniões, que possibilite uma educação efetiva e fortalecedora do conhecimento crítico-reflexivo em enfermagem/saúde ${ }^{(18)}$. O rompimento com a rotina diária, por meio do exercício da reflexão, do diálogo, do agir e do pensar, dá significado à autonomia e ao pensamento crítico educativo ${ }^{(14,17,20)}$. O processo de pensar emerge como o processo da coletividade e do pertencimento profissional, em que o pensar deve ser evidenciado como uma prática humana de decisão compartilhada, e não como um desempenho individual ${ }^{(15)}$.

Hannah Arendt aborda a condição humana e a sua temporalidade pautada na prática política do ser humano na tríade de atuações: suprimento das necessidades biológicas humanas (bomo laborans), a forma de transformar a natureza em 
objetos duráveis compartilhados pelos seres humanos (homo faber), e a ação ligada à forma em que se dá o relacionamento entre os homens e a sua condição política ${ }^{(11)}$.

Em "A Condição Humana"(11), o pensar era inspirado na experiência pessoal. Seus interesses diziam respeito aos fenômenos políticos humanos e às questões ontológicas e metafísicas acerca da natureza e do universo. A condição humana representa situações relacionadas à existência e ao pertencimento do homem a determinado lugar. Pensando na enfermagem, a necessidade de sentir-se pertencente a uma profissão é essencial para a sua consolidação e para o fortalecimento da relação das pessoas nela envolvidas.

Sentir-se pertencente à Enfermagem, no sentido de uma coesão, fortalecendo a cooperação e a relação interpessoal, levará os profissionais a ações discursivas-políticas-sociais em favor da enfermagem/saúde, diminuindo os conflitos ético-profissionais e construindo uma solidariedade na Enfermagem ${ }^{(14,19,20)}$. O trabalho em equipe também deve ser fortalecido por meio de ações horizontais e integradas, aglutinando o saber entre os sujeitos e valorizando a singularidade dos profissionais envolvidos no processo de trabalho em Enfermagem ${ }^{(19)}$. Essas atitudes de pertencimento refletirão positivamente na visibilidade profissional e, consequentemente, no trabalho prestado. Quando o profissional da enfermagem percebe-se como peça essencial da equipe de enfermagem, ele reconhece o valor e a importância desse fazer profissional coletivo e a dimensão coletiva desse cuidado na sociedade. Querer pertencer e se sentir pertencente à classe profissional da enfermagem pode gerar uma percepção de responsabilidade coletiva. Isso poderá refletir na aceitação da condição humana dos profissionais da saúde.

\section{Conclusão}

A reflexão sobre a ética no fazer profissional da enfermagem, levando em consideração os conceitos de condição humana e de banalidade do mal de Hannah Arendt, reforça a importância dos profissionais de enfermagem em assumir uma postura crítico-reflexiva e ética de não julgamento. Deve-se almejar profissionais da enfermagem que possam articular problemas complexos dentro de seus contextos e buscar compreender as ações, e não culpabilizar os indivíduos. Nestas reflexões do fazer profissional, não se exime a responsabilidade individual dentro da ética do fazer em enfermagem, porém se propõe um novo olhar à luz de um entendimento das ações humanas (no qual compreende-se que o profissional da enfermagem possui uma condição humana).

A postura crítica-reflexiva deve permear o processo de cuidar desde a formação, como inerente ao fazer/ser profissional de enfermagem. Essa dimensão não deve ser considerada menos importante do que outras ações desenvolvidas pela Enfermagem. Acredita-se que os conceitos de Hannah Arendt revelam-se essenciais para a ética na enfermagem, por favorecerem a tentativa de encontrar novas soluções para os desafios existentes no campo profissional, por meio de uma ética que compreenda a complexidade da condição humana (labor, trabalho, ação) e perpasse a banalidade do mal. Cabe destacar que a educação permanente e continuada em saúde, trabalho em equipe e sentimento de pertencimento à profissão de enfermagem são vistos como estratégias para o crescimento e a visibilidade profissional, assumindo-se que a incapacidade de pensar pode ser relacionada com o ambiente privilegiado para o fracasso moral.

Por meio da reflexão ética, o ser humano profissional pode tornar-se uma pessoa-enfermeiro-pensante, que é capaz de agir eticamente dentro da sua condição humana. Logo, será estimulado o pensar ético, juntamente com os colegas de equipe, dentro das condições de trabalho vivenciadas, preservando a empatia para o lidar com seus pacientes. Assim, evita-se que a mecanização do cuidado e a ocorrência de eventos não éticos tornem-se banais na rotina da assistência de enfermagem focada em encontrar culpados, e não em assumir soluções conjuntas. 


\section{Colaborações:}

1 - concepção, projeto, análise e interpretação dos dados: Camila Biazus Dalcin, Rafaela Serpa, Evangelia Kotzias Atherino dos Santos, Francis Solange Vieira Tourinhon e Patrícia Kuerten Rocha;

2 - redação do artigo e revisão crítica relevante do conteúdo intelectual: Camila Biazus Dalcin, Rafaela Serpa, Evangelia Kotzias Atherino dos Santos, Francis Solange Vieira Tourinhon e Patrícia Kuerten Rocha;

3 - aprovação final da versão a ser publicada: Camila Biazus Dalcin, Rafaela Serpa, Evangelia Kotzias Atherino dos Santos, Francis Solange Vieira Tourinhon e Patrícia Kuerten Rocha.

\section{Referências}

1. Pires DEPD, Bellaguarda MGR, Matos ATZE, editores. Consolidação da legislação e ética profissional [Internet]. Florianópolis: Conselho Regional de Enfermagem; 2013 [cited 2017 Jun 13]. Available from: http://www.corensc.gov.br/ wp-content/uploads/2015/03/Serie_Cadernos_ Enfermagem_Vol01.pdf

2. Backes DS, Backes MS, Erdmann AL, Büscher A, Salazar-Maya AM. Significado da prática social do enfermeiro a partir do Sistema Único de Saúde brasileiro. Aquichan [Internet]. 2014 [cited 2017 Jun 4];14(4):560-70. Available from: https:// www.researchgate.net/publication/273310696_ Significado_da_pratica_social_do_enfermeiro_ com_e_a_partir_do_Sistema_Unico_de_Saude_ brasileiro

3. Vieira A, Alves M, Monteiro PRR, Garcia FC. Mulheres nas equipes de enfermagem: identificação organizacional e vivências de prazer e sofrimento. Rev Latino-Am Enfermagem [Internet]. 2013 [cited 2017 Jun 12];21(5):1127-36. Available from: http:// www.scielo.br/pdf/rlae/v21n5/pt_0104-1169rlae-21-05-1127.pdf

4. Schneider DG, Ramos FRS. Nursing ethical processes in the State of Santa Catarina: characterization of factual elements. Rev Latino-Am Enfermagem [Internet]. 2012 [cited 2017 Jul 2]; 20(4):744-52. Available from: http:// www.scielo.br/pdf/rlae/v20n4/15.pdf
5. Mattozinho FCB, Freitas GF. Nursing ethical issues occurring within the State of São Paulo: factual description. Acta paul enferm [Internet]. 2015 Dec [cited 2017 Jul 14];28(6):593-600. Available from: http://www.scielo.br/scielo.php?script $=$ sci_ arttext\&pid=S0103-21002015000600593\&lng=en

6. Vargas I, Concha CA. Moral Distress, Sign of Ethical Issues in the Practice of Oncology Nursing: Literature Review. Aquichan. 2019;19(1):e1913. DOI: 10.5294/aqui.2019.19.1.3

7. Haghighinezhad G, Atashzadeh-Shoorideh F, Ashktorab T, Mohtashami J, Barkhordari-Sharifabad M. Relationship between perceived organizational justice and moral distress in intensive care unit nurses. Nurs Ethics. 2017;26(2)460-70. DOI: 10.1177/0969733017712082

8. Oh Y, Gastmans C. Moral distress experienced by nurses: a quantitative literature review. Nurs Ethic. 2015 Feb;22(1):15-31.

9. Nunes L. Ethical problems identified by nurses in relation to patients in critical condition. Rev bioét [Internet]. 2015 Apr [cited 2017 Jul 14];23(1):187-99. Available from: http://www. scielo.br/scielo.php?script=sci_arttext\&pid=\$1983$80422015000100187 \& \operatorname{lng}=\mathrm{pt}$

10. Nora CRD, Zoboli ELCP, Vieira M. Ethical problems experienced by nurses in primary health care: integrative literature review. Rev Gaúcha Enferm [Internet]. 2015 Mar [cited 2017 Jul 14];36(1):112-21. Available from: http://www. scielo.br/scielo.php?script=sci_arttext\&pid=S1983$14472015000100112 \& \operatorname{lng}=\mathrm{en}$

11. Hannah A. A condição humana. 10a ed. Tradução Roberto Raposo. Rio de Janeiro: Forense Universitária; 2005.

12. Hannah A. A dignidade da política: ensaios e conferências. Tradução Antonio Abranches. Rio de Janeiro: Relume Dumará; 1993.

13. Hannah A. Eichmann em Jerusalém: um relato sobre a banalidade do mal. Tradução José Rubens Siqueira. São Paulo: Companhia das Letras; 1999.

14. Backes DS, Backes MS, Dalcin CB, Erdmann AL. Sistema de cuidado de enfermagem na perspectiva luhmanniana. Rev Latino-Am Enfermagem [Internet]. 2012 set/out [cited 2017 Jun 11];20(5):873-9. Available from: http://www. scielo.br/pdf/rlae/v20n5/pt_08.pdf 
15. Oliveira Salimena AM, Elias EA, Oliveira Souza IE, Vieira LB. Falatório e ocupação no cotidiano das profissionais de enfermagem no cuidado de si e do outro. Rev baiana enferm [Internet]. 2016 [cited 2017 Jun 11];30(1):316-24. Available from: https://portalseer.ufba.br/index.php/enfermagem/ article/view/14393/pdf_27

16. Siqueira JE. Irreflexão e a banalidade do mal no pensamento de Hannah Arendt. Bioethikos [Internet]. 2011 [cited 2017 May 24];5(4):392-400. Available from: https://www.saocamilo-sp.br/pdf/ bioethikos/89/A5.pdf

17. Andrade M. A banalidade do mal e as possibilidades da educação moral: contribuições arendtianas. Rev bras educ [Internet]. 2010 [cited 2017 May 24];15(43):109-25. Available from: http://www. scielo.br/pdf/rbedu/v15n43/a08v15n43.pdf

18. Silva LAA, Pinno C, Schmidt SMS, Noal HC, Gomes IEM, Signor E. A educação permanente no processo de trabalho de enfermagem. Rev enferm Cent-Oeste Min [Internet]. 2016 [cited 2017 Jun 5];6(3):2349-61. Available from: http:// www.seer.ufsj.edu.br/index.php/recom/article/ view/1027/1168

19. Santos SSBS, Silva LS, Carneiro EKN, Santana Carvalho ES. Processo de trabalho da equipe de Enfermagem em Unidades Saúde da Família em município baiano. Rev baiana enferm [Internet]. 2013 [cited 2017 Jun 26];27(2):101-7. Available from: https://portalseer.ufba.br/index.php/enfermagem/ article/view/8850/7154

20. Silva TN, Freire MEM, Vasconcelos MF, Silva Jr SV, Silva WJC, Araújo PS, et al. Deontological aspects of the nursing profession: understanding the code of ethics. Rev Bras Enferm. 2018;71(1):3-10. DOI: 10.1590/0034-7167-2016-0565

21. Bratz JKA, Sandoval-Ramirez M. Ethical competences for the development of nursing care. Rev Bras Enferm. 2018;71(Suppl 4):1810-4. DOI: 10.1590/0034-7167-2017-0539

22. Eldh AC, Zijpp T, McMullan C, McCormack B, Seers K, Rycroft-Malone J. 'I have the world's best job'- staff experience of the advantages of caring for older people. Scand J Caring Sci [Internet]. 2016 [cited 2017 Jul 5];30(2):365-73. Available from: http://onlinelibrary.wiley.com/doi/10.1111/ scs.12256/full

23. Mesquita AC, Zamarioli CM, Fulquini FL, Carvalho EC, Angerami ELS. As redes sociais nos processos de trabalho em enfermagem: revisão integrativa da literatura. Rev Esc Enferm USP. 2017;51:e03219. DOI: $10.1590 / \mathrm{s} 1980-220 \times 2016021603219$.

24. Ventola CL. Social media and health care professionals: benefits, risks, and best practices. P T. 2014;39(7):491-9.

Recebido: 21 de fevereiro de 2019

Aprovado: 17 de outubro de 2019

Publicado: 10 de dezembro de 2019

A Revista Baiana de Enfermagem utiliza a Licença Creative Commons - Atribuição-NãoComercial 4.0 Internacional. https://creativecommons.org/licenses/by-nc/4.0/

Este artigo é de acesso aberto distribuído sob os termos da Licença Creative Commons (CC BY-NC). Esta licença permite que outros remixem, adaptem e criem a partir do seu trabalho para fins não comerciais. Embora os novos trabalhos tenham de lhe atribuir o devido crédito e não possam ser usados para fins comerciais, os usuários não têm de licenciar esses trabalhos derivados sob os mesmos termos. 